\title{
NILAI PERDAGINGAN SAPI AUSTRALIAN COMMERCIAL CROSS DARI JENIS KELAMIN YANG BERBEDA
}

\author{
Harapin Hafid H.', H. R. Eddie Gurnadi ${ }^{2}$, Rudy Priyanto ${ }^{2}$ dan Asep Saefuddin ${ }^{3}$
}

\section{INTISARI}

Meningkatnya permintaan pasar saat ini terhadap produk peternakan khususnya daging sapi tidak dapat dipenuhi dengan baik karena rendahnya kuantitas dan kualitas sapi lokal di Indonesia. Untuk menjamin keseimbangan pasar dan memenuhi permintaan tersebut, dilakukan impor daging beku dan sapi bakalan dari Australia. Sapi impor yang banyak digunakan dalam industri feedlot di Indonesia adalah bangsa Australian Commercial Cross (ACC). Tujuan penelitian ini adalah untuk mengetahui nilai perdagingan pada sapi Australian Commercial Cross dengan jenis kelamin yang berbeda. Sebanyak 65 karkas sapi ACC digunakan dalam penelitian ini. Rancangan acak lengkap digunakan untuk melihat pengaruh klasifikasi jenis kelamin sapi. Peubah yang diamati adalah bobot karkas panas, bobot karkas dingin, tebal lemak subkutan rusuk 12-13, luas areal otot mata rusuk (udamaru), bobot potongan komersial, nilai perdagingan berdasarkan klasifikasi USDA pada bagian round, loin, rib dan chuck. Hasil penelitian menunjukkan bahwa secara umum karakteristik karkas tidak dipengaruhi oleh jenis kelamin sapi, kecuali pada persentase lemak pelvis, ginjal, dan jantung di mana cow nyata lebih besar dibandingkan heifer dan steer. Nilai potongan total daging primer berbeda pada potongan chuck dan round dimana steer dan heifer mempunyai persentase yang lebih tinggi dibandingkan cow, sedangkan total potongan daging sekunder pada sapi steer lebih tinggi daripada heifer dan cow. Terdapat perbedaan persentase nilai perdagingan yang dihitung berdasarkan rumus Murphey. Steer mempunyai nilai perdagingan lebih baik dibandingkan heifer dan cow. Persentase perdagingan berdasarkan penimbangan langsung tidak dipengaruhi jenis kelamin. Berdasarkan USDA nilai perdagingan, cow, heifer, dan steer memiliki nilai antara 3 dan 5 . Steer memiliki nilai perdagingan 3 , heifer 4 , dan cow memiliki nilai 5 . Hal ini menunjukkan bahwa perdagingan steer lebih baik dibandingkan heifer dan cow.

(Kata kunci: Nilai perdagingan, Sapi Australian Commercial Cross, Jenis kelamin).

Buletin Peternakan 28(2): 72 - 79, 2004

\footnotetext{
'Jurusan Produksi Ternak Fakultas Pertanian, Universitas Haluoleo Kendari.

${ }^{2}$ Fakultas Peternakan Institut Pertanian Bogor, Bogor.

${ }^{3}$ Fakultas MIPA Institut Pertanian Bogor, Bogor.
} 


\title{
THE YIELD GRADE OF AUSTRALIAN COMMERCIAL CROSS CATTLES OF DIFFERENT SEX
}

\begin{abstract}
Domestic demand on beef is increasing today. However the beef supply can not fulfil the demand so that import of beef and feeder cattle is still required. Beef cattle feedlotting is now growing in Indonesia. The industry utilize feeder cattle imported from Australia such as Australian Commercial Cross (ACC) of different sex categories. The aims of this study were to examine the influence of different sex categories (cow, heifer, and steer) on beef yield grade of Australian Commercial Cross cattle's raised in feedlot. Sixty five carcass from Australian Commercial Cross cattle were used in this research. Completely randomized design used to study the influence of the cattle's sex. Variable being observed were those of hot carcass weight, cold carcass weight, 12th rib fat thickness, loin eye area, kidney, pelvic and heart fats, wholesale cuts weight, and beef yield in the round, loin, rib and chuck according to USDA specification. Result of the research showed the generally characteristic carcass were not influenced by cattle's sex, the exception were noticed on fat percentages of kidney, pelvic, and heart where in cows were found higher compared to heifer and steer. Cut all of the yield first compare the cut chuck and round where steer and heifer have a percentage higher to comparer cow, cut to second cattle, steer higher from heifer and cow. There is a compare to percentage of the yield cattle counted to the base formula's Murphey, when steer have value cattle's the better than heifer and cow. Percentage of the yield grade based based on weighed direct isn't influence with in sex difference. Based on USDA yield grade cow, heifer and steer have to a value or yield grade range 3 and 5 . Steer have value yield grade 3 , heifer have value yield grade 4 and cow have value yield grade 5 . This case showed that the yield grade steer better than heifer and cow cattle's.
\end{abstract}

(Key words : Cattle, Cow, Heifer, Steer, Yield grade).

\section{Pendahuluan}

Saat ini permintaan pasar domestik terhadap produk peternakan khususnya daging sapi cenderung meningkat dari tahun ke tahun. Namun produksi sapi potong lokal, baik dari segi kuantitas maupun kualitas, masih terbatas sehingga tidak dapat memenuhi kebutuhan pasar domestik. Untuk memenuhi kebutuhan dan kekurangan daging, maka dilakukan impor sapi bakalan dan daging beku. Sapi bakalan yang diimpor ke Indonesia umumnya berasal dari Australia contohnya adalah sapi ACC.

Sapi-sapi bakalan impor digemukkan secara feedlot menggunakan pakan berenergi tinggi, sehingga dalam waktu yang singkat dapat diperoleh pertambahan bobot badan yang tinggi dan menghasilkan sapi dengan komposisi karkas yang ideal yaitu karkas dengan daging yang tinggi serta tulang dan lemak yang rendah sesuai dengan spesifikasi pasar.

Dewasa ini, permintaan konsumen dari pasar khusus sangat mensyaratkan mutu (grade) karkas yang dihasilkan. Standar mutu biasanya mengacu pada nilai perdagingan (USDA yield grade) (Kempster et al,, 1982, dan Romans et al. 1994). Penelitian ini bertujuan untuk melakukan pengujian terhadap standar mutu nilai perdagingan yang dikembangkan USDA hubungannya dengan spesifikasi pasar di Indonesia.

\section{Materi dan Metode}

Penelitian ini menggunakan sapi hasil persilangan dari bangsa ACC. Sapi-sapi ini memiliki umur berkisar antara 1-4 tahun. Jumlah sapi yang digunakan dalam penelitian ini sebanyak 65 ekor yang terdiri dari : steer (jantan kastrasi) 23 ekor, heifer (dara) 20 ekor, dan cow (induk) 22 ekor.

Peralatan dan fasilitas yang digunakan adalah plastik grid untuk pengukuran luas urat daging mata rusuk; mistar untuk mengukur tebal lemak subkutan; timbangan sapi hidup; timbangan karkas; timbangan untuk mengukur lemak pelvis; ginjal dan jantung; timbangan daging dan peralatan abattoir dari RPH. 
Ternak sapi sebelum dipotong dipuasakan terlebih dahulu selama 24 jam untuk menghindari variasi isi saluran pencernaan. Setelah itu, sapi ditimbang untuk menentukan bobot potongnya. Penyembelihan secara halal dengan prosedur yang telah diakui. Karkas yang diperoleh ditimbang dan disimpan dalam chilling room pada suhu $2-5^{\circ} \mathrm{C}$ selama 24 jam. Setelah 24 jam karkas ditimbang untuk mendapatkan bobot karkas dingin. Pada karkas dingin dilakukan pengukuran tebal lemak punggung dan luas areal otot mata rusuk pada irisan antara rusuk ke 12 dan 13. Penimbangan lemak ginjal, pelvis, dan jantung dilakukan saat dilakukan proses eviscerasi.

Boning karkas dilakukan menurut standar Australian Meat and Livestock Corporation (2001) karkas dibagi dalam 16 potongan daging yang terdiri atas seperempat karkas bagian depan (forequarter), yaitu chuck, chuck tender, blade, cuberoll, shortrib, brisket, dan shin, dan seperempat karkas bagian belakang (hindquarter), yaitu loin (sirloin), tenderloin, flank, knuckle, rump, topside, silverside, shank, dan oxtail. Hasil sampingan potongan karkas berupa trim lemak, serpihan daging dan tulang ditimbang dan dicatat sebagai bobot trim lemak, serpihan daging dan tulang. Potongan daging menurut USDA diperoleh berdasarkan aproksimasi dari 16 potongan daging tersebut, seperti terlihat pada Tabel 1.

Peubah yang diamati dalam penelitian ini adalah bobot karkas panas, bobot karkas dingin, tebal lemak subkutan rusuk 12-13, luas areal otot mata rusuk (udamaru), bobot potongan komersial, nilai perdagingan. Nilai perdagingan dihitung menggunakan rumus yang dikembangkan oleh Murphey et al. (1960) sebagai berikut.

Nilai perdagingan $=51,34-5,784$ [tebal lemak punggung (inchi)] - 0,46 [persentase lemak pelvis, ginjal dan jantung] $+0,74$ [luas daging mata rusuk (inchi $\left.i^{2}\right)$ ] - 0,0093 [bobot karkas (pounds)].

Persentase potongan komersial daging chuck, rib, loin dan round yang telah diperolch kemudian dimasukkan ke dalam nilai perdagingan seperti pada Tabel 2 .

Tabel 1. Potongan komersial daging menurut USDA berdasarkan aproksimałsi 16 potongan komersial daging (Sixteen commercial cuts according to USDA)

\begin{tabular}{|c|c|c|}
\hline \multirow[t]{2}{*}{ Potongan daging (Primal cuts) } & \multicolumn{2}{|r|}{ Potongan komersial (Commercial cut) } \\
\hline & USDA & $\begin{array}{l}\text { Australian Meat and Livestock } \\
\text { Cooperation }\end{array}$ \\
\hline \multirow[t]{4}{*}{$\begin{array}{l}\text { Potongan primer } \\
\text { (Primary cuts) }\end{array}$} & Chuck & $\begin{array}{l}\text { Chuck } \\
\text { Blade } \\
\text { Chuck tender }\end{array}$ \\
\hline & Rib & $\begin{array}{l}\text { Shortrib } \\
\text { Cuberoll }\end{array}$ \\
\hline & Loin & $\begin{array}{l}\text { Tenderloin } \\
\text { Striploin } \\
\text { Rump }\end{array}$ \\
\hline & Round & $\begin{array}{l}\text { Knuckle } \\
\text { Topside } \\
\text { Silverside } \\
\text { Shank }\end{array}$ \\
\hline \multirow{4}{*}{$\begin{array}{l}\text { Potongan sekunder } \\
\text { (Secondary cuts) }\end{array}$} & Brisket & Brisket \\
\hline & Plate & \\
\hline & Flank & Flank \\
\hline & Shin & Shin \\
\hline
\end{tabular}


Tabel 2. Hubungan antara USDA Yield Grade dengan persentase potongan komersial daging chuck, rib, loin dan round (The relationship between USDA yield grade and percentage of commercial cut : chuck, rib, loin and round)

\begin{tabular}{cc}
\hline $\begin{array}{c}\text { Nilai perdagingan } \\
\text { (Yield grade) }\end{array}$ & $\begin{array}{c}\text { Persentase potongan komersial daging chuck, rib, loin dan round } \\
\text { (Percentage of commercial cuts }: \text { chuck, rib, loin and round) }\end{array}$ \\
\hline 1 & $52,3<$ \\
2 & $50,0-52,3$ \\
3 & $47,7-50,0$ \\
4 & $45,4-47,7$ \\
5 & $<45,4$ \\
\hline
\end{tabular}

Sumber (Source) : Kempster et al. (1982).

Rancangan percobaan yang digunakan adalah Rancangan Acak Lengkap (Steel dan Torrie, 1993). Data dianalisis menggunakan Analisis Peragam dengan indikator-indikator nilai perdagingan sebagai faktor koreksi. Model matematika yang digunakan adalah sebagai berikut:

Dimana :

$$
Y i j k=a+J K i+X i j+\varepsilon i j
$$

Yijk = Persentase hasil daging pada potongan chuck, rib, loin dan round ke-k dari a $=$ Intersep bangsa ke-i dan jenis kelamin ke-j

$\mathrm{JKi}=$ Pengaruh tetap jenis kelamin ke-j

$\mathrm{Xij}=$ Pengaruh bobot karkas panas, tebal lemak subkutan rusuk 12-13, luas areal otot mata rusuk dan persentase lemak pelvis, ginjal dan jantung sebagai kovariabel

$\varepsilon \mathrm{ij}=$ Standarerror

Analisis data dilakukan dengan program SAS V6.12 menggunakan prosedur General Linier Model (GLM), kemudian dilakukan Least Square Means (LSM) untuk menguji perbedaan di antara perlakuan.

\section{Hasil dan Pembahasan}

Penilaian perdagingan terhadap karkas perlu dilakukan untuk mengetahui kualitas dan kuantitas potongan karkas yang dapat dijual. Burson (1997), dan Jones and Stringer (1999) menyatakan ukuran untuk menentukan nilai potongan karkas adalah tebal lemak punggung, luas areal otot mata rusuk, persentase lemak pelvis, ginjal, dan jantung serta bobot karkas panas.

Tabel 3 menyajikan karakteristik karkas sapi $\mathrm{ACC}$ pada jenis kelamin yang berbeda.

Hasil penelitian menunjukkan bahwa bobot karkas panas, tebal lemak subkutan rusuk $12-13$, dan luas urat daging mata rusuk tidak dipengaruhi oleh klasifikasi jenis kelamin sapi. Sedangkan Persentase lemak pelvis, ginjal, dan jantung menunjukkan perbedaan yang nyata. Persentase lemak ginjal, pelvis, dan jantung yang diperoleh menunjukkan bahwa cow mempunyai persentase lemak ginjal, pelvis, dan jantung yang lebih tinggi dibandingkan heifer dan steer. Perbedaan ini kemungkinan disebabkan perbedaan umur dimana cow lebih tua (mature) dibandingkan steer dan heifer: Besarnya kandungan lemak ginjal, pelvis, dan jantung pada cow sesuai Romans et al. (1985) yang menyatakan bahwa kandungan lemak ginjal, pelvis dan jantung pada sapi sebesar $3,5 \%$. Griffin et al. (1992) memperoleh kandungan lemak ginjal, pelvis dan jantung sebesar $2,1 \%$ pada steer dan heifer sapi potong dan perah.

Potongan-potongan komersial jika dinyatakan sebagai persentase terhadap bobot karkas dingin pada masing-masing bangsa dan jenis kelamin terlihat pada Tabel 4.

Tabel 4 memperlihatkan rataan persentase potongan komersial daging berdasarkan USDA yang dikoreksi terhadap bobot karkas panas yang sama. Hasil penelitian menunjukkan bahwa jenis kelamin mempengaruhi persentase total potongan daging primer, khususnya persentase daging chuck dan round $(\mathrm{P}<0,05)$. Terlihat bahwa Steer dan heifer mempunyai persentase chuck yang 
Tabel 3. Rataan bobot karkas panas, tebal lemak subkutan rusuk 12-13, luas areal otot mata rusuk, persentase lemak pelvis, ginjal dan jantung (Hot carcass weight, subcontinents fat thickness of $12-13$ rib, loin eye area \% if of pelvic, kidney and heart)

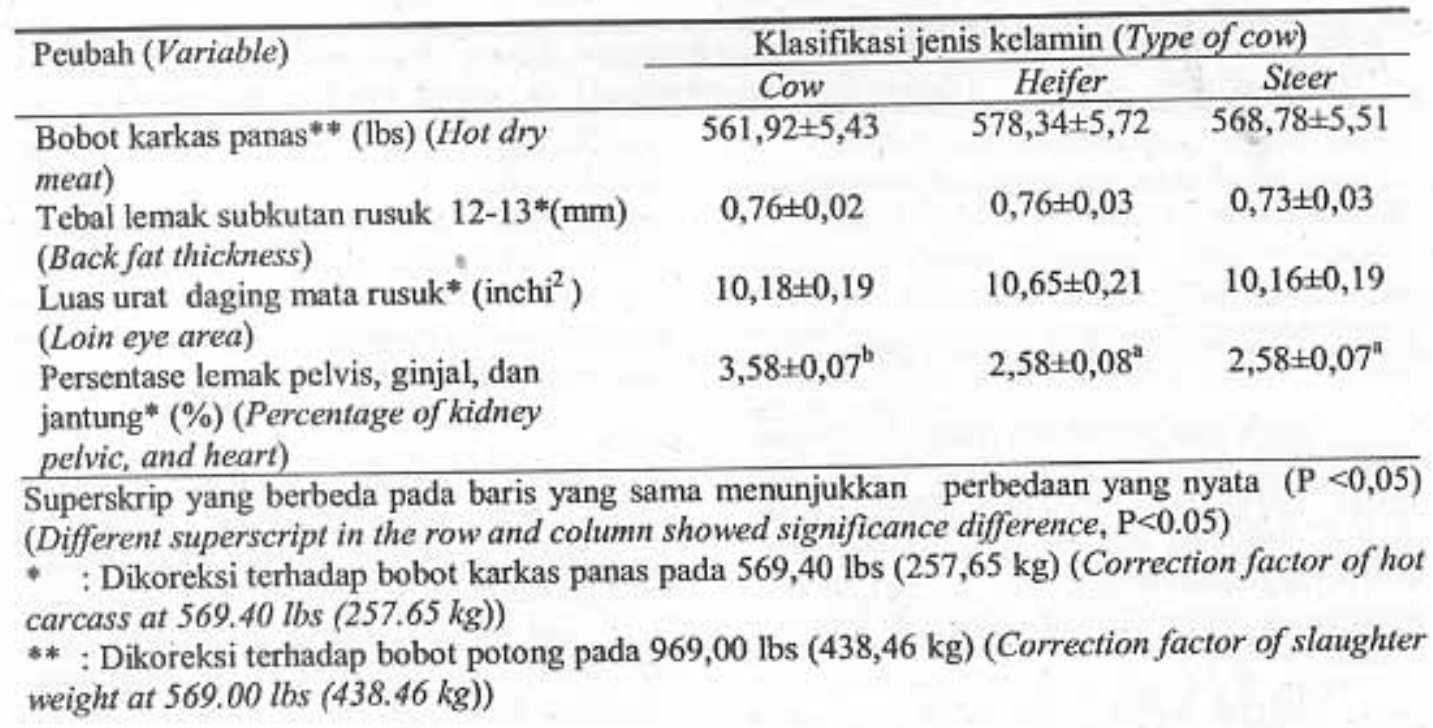

Tabel 4. Rataan persentase potongan daging menurut USDA dengan jenis kelamin berbeda* (Percentage of primal cuts of different types of cattle according to ${ }_{4}$ USDA)

\begin{tabular}{|c|c|c|c|c|}
\hline \multirow{3}{*}{\multicolumn{2}{|c|}{ Potongan daging (Primal cuts) }} & \multicolumn{3}{|c|}{ Klasifikasi jenis kelamin (Types of cattle) } \\
\hline & & Cow & Heifer & Steer \\
\hline & & \multicolumn{3}{|c|}{$\ldots$} \\
\hline Potongan primer & Chuck & $16,84 \pm 0,31^{2}$ & $18,09 \pm 0,33^{b}$ & $18,55 \pm 0,31^{b}$ \\
\hline \multirow{4}{*}{ (Primary cut) } & Rib & $4,03 \pm 0,11$ & $4,17 \pm 0,12$ & $3,76 \pm 0,11$ \\
\hline & Loin & $9,62 \pm 0,16$ & $9,89 \pm 0,17$ & $9,81 \pm 0,16$ \\
\hline & Round & $16,39 \pm 0,27^{\mathrm{a}}$ & $18,20 \pm 0,29^{b}$ & $18,18 \pm 0,27^{b}$ \\
\hline & Total & $46,88 \pm 0,48^{\mathrm{a}}$ & $50,34 \pm 0,52^{b}$ & $50,30 \pm 0.48^{b}$ \\
\hline Potongan & Brisket & $4,29 \pm 0,10^{\mathrm{n}}$ & $4,26 \pm 0,11^{2}$ & $4.68 \pm 0,10^{\mathrm{b}}$ \\
\hline sekunder & Flank & $4,56 \pm 0,14^{b}$ & $4,02 \pm 0,15^{\mathrm{a}}$ & $4,68 \pm 0,14^{\mathrm{b}}$ \\
\hline \multirow[t]{2}{*}{ (Secondary cut) } & Shin & $1,69 \pm 0,03^{2}$ & $1,90 \pm 0,03^{b}$ & $1,94 \pm 0,03^{b}$ \\
\hline & Total & $10.54 \pm 0.18^{\mathrm{a}}$ & $10.19 \pm 0,19^{a}$ & $11,31 \pm 0,18^{b}$ \\
\hline Total (Total) & & $57,42 \pm 0,50^{2}$ & $60,53 \pm 0,54^{b}$ & $61,61 \pm 0,51^{b}$ \\
\hline
\end{tabular}

Superskrip yang berbeda pada baris yang sama menunjukkan hasil berbeda nyata, $\mathrm{P}<0,05$ (Superscripts in the same row and column showed significant difference, $P<0.05$ )

* = Dikoreksi terhadap bobot karkas panas pada $569,40 \mathrm{lbs}(257,65 \mathrm{~kg})$ (Correction factor of slaughter weight at $569.40 \mathrm{lbs}(257.65 \mathrm{~kg})$. 
dan $18,09 \%$ vs $16,84 \%$ ). Hal ini menunjukkan bahwa potongan chuck pada steer dan heifer berkembang lebih baik dibandingkan cow. Hal yang sama juga pada potongan round dimana steer mempunyai persentase round sebesar $18,18 \%$, heifer $(18,20 \%)$ yang berbeda nyata dengan cow $(16,39 \%)$. Hasil yang diperoleh Reiling et al. (1992) adalah persentase chuck dan round : sebesar $19,2 \%$ dan $14,1 \%$ (Bull), $14,8 \%$ dan $12,6 \%$ (steer), $16,6 \%$ dan $13,5 \%$ (heifer).

Pada potongan-potongan daging sekunder, pengaruh dari jenis kelamin lebih terlihat. Steer memiliki persentase total potongan daging sekunder dan persentase potongan-potongan daging sekunder yaitu brisket, flank dan shin yang lebih tinggi daripada sapi heifer dan cow. Persentase potongan daging sekunder dipengaruhi oleh jumlah lemak yang terdapat pada karkas dimana potongan daging sekunder memiliki lemak yang lebih tinggi daripada primer.

Secara keseluruhan, terlihat bahwa total daging dipengaruhi secara nyata oleh jenis kelamin. Steer dan heifer memiliki persentase total daging yang yata lebih tinggi daripada cow $(61,61 \%$ dan $60,53 \%$ VS $57,42 \%)$. Perbedaan persentase daging dipengaruhi oleh pertumbuhan lemak dan tingkat kedewasaan ternak. Steer dan heifer mempunyai tingkat kedewasaan yang lebih cepat daripada cow. Pada bangsa yang sama, steer dan heifer akan lebih cepat gemuk pada bobot yang lebih ringan daripada steer dan juga akan lebih cepat gemuk ketika masuk fase penggemukkan (Preston dan Willis, 1982).

Penilaian perdagingan ini dapat dilakukan dengan menggunakan rumus yang dikembangkan oleh Murphey et al. (1960) dengan indikator-indikator tertentu, yaitu tebal lemak punggung, luas areal otot mata rusuk, persentase lemak pelvis, ginjal, dan jantung, dan bobot karkas panas, serta potonganpotongan daging tertentu yaitu chuck, rib, loin dan round.

Tabel 5 memperlihatkan persentase perdagingan yang dihitung berdasarkan rumus Murphey et al. (1960) dan berdasarkan penimbangan langsung.

Hasil analisis statistik menunjukkan bahwa persentase perdagingan yang dihitung berdasarkan rumus dipengaruhi jenis kelamin.
Persentase perdagingan pada steer berbeda nyata lebih besar dibandingkan cow dan heifer. Perbedaan persentase perdagingan ini disebabkan karena adanya perbedaan indikator perdagingan yaitu perbedaan persentase lemak pelvis, ginjal, dan jantung di antara jenis kelamin.

Berdasarkan penimbangan langsung, secara statististik, jenis kelamin tidak nyata mempengaruhi persentase perdagingan dengan penimbangan langsung. Pada Tabel 5 terlihat bahwa persentase perdagingan dengan penimbangan langsung relatif lebih tinggi 1$2 \%$. Hal ini menunjukkan bahwa penggunaan rumus Murphey cenderung under estimate dengan bias $1-2 \%$. Perbedaan ini disebabkan perbedaan cutting dan trimming lemak antara Australia dan USDA, di mana Australia cenderung menghendaki lemak yang lebih tebal sehingga persentase perdagingan dengan penimbangan langsung akan lebih tinggi dibandingkan persentașe perdagingan berdasarkan rumus.

Persentase perdagingan yang diperoleh dengan menggunakan rumus Murphey et al. (1960) kemudian dialokasikan ke dalam nilai yield grade dan dihitung frekuensinya. Tabel 6 menyajikan frekuensi nilai perdagingan (USDA Yield Grade) sapi ACC dan BX dengan jenis kelamin steer dan heifer:

Tabel 6 menunjukkan bahwa cow, heifer dan steer memiliki nilai perdagingan 3,4 dan 5 . Cow mempunyai frekwensi nilai pedagingan terbanyak pada YG $5(81.82 \%)$, heifer pada YG $4(65 \%)$ dan steer pada YG $3(39.13 \%)$. Nilai perdagingan yang lebih rendah (YG 1) menunjukkan bahwa sapi-sapi ini mempunyai kualitas hasil daging yang kurang baik karena kurang mengandung lemak. Nilai perdagingan dan persentase perdagingan mempunyai hubungan yang negatif, semakin kecil nilai perdagingan maka persentase perdagingan suatu karkas semakin tinggi. Ngadiyono (1995) dan Hanson et al. (1999) menyatakan bahwa dengan semakin tinggi nilai perdagingan maka persentase perdagingan karkas akan semakin rendah dan perlemakan meningkat.

Tabel 6 menunjukkan bahwa sapi steer memiliki nilai perdagingan 3 dengan proporsi daging dan lemak lebih baik dibandingkan heifer (YG 4) dan cow (YG 5) yang mempunyai proporsi lemak lebih tinggi dengan daging. 
Tabel 5. Persentase chuck, rib, loin dan round berdasarkan rumus dan penimbangan langsung*

(Percentage of chuck, rib, loin and round based on formula and direct weighing)

\begin{tabular}{lccc}
\hline \multirow{2}{*}{$\begin{array}{l}\text { Persentase Chuck, Rib, Loin dan Round } \\
\text { (Percentage of chuck, rib, lion, and round) }\end{array}$} & \multicolumn{3}{c}{ Klasifikasi jenis kelamin (Type of cattle) } \\
\cline { 2 - 4 } & Cow & Heifer & Steer \\
\hline $\begin{array}{l}\text { Berdasarkan rumus (Based on formula's } \\
\text { Murphey) }\end{array}$ & $47,42 \pm 0,37^{\mathrm{a}}$ & $47,71 \pm 0,39^{\mathrm{bN}}$ & $48,81 \pm 0,37^{\mathrm{bB}}$ \\
\hline $\begin{array}{l}\text { Berdasarkan penimbangan langsung (Based } \\
\text { on weighed direct) }\end{array}$ & $47,68 \pm 1,00$ & $49,76 \pm 0,74$ & $50,04 \pm 0,63$ \\
& & & \\
\hline
\end{tabular}

Superskrip huruf kecil yang berbeda pada baris dan kolom yang sama menunjukkan hasil berbeda nyata ( $\mathrm{P}<0,05)$; (Superscripts of small character in the same row and column showed significant difference, $P<0.05$ )

Superskrip huruf besar yang berbeda pada baris dan kolom yang sama menunjukkan hasil berbeda nyata ( $\mathrm{P}<0,01)$ (Superscripts of capital character in the same row and column showed significant difference, $\mathrm{P}<0.01$ )

* Dikoreksi terhadap bobot karkas panas, tebal lemak subkutan rusuk 12-13, luas areal otot mata rusuk dan persentase lemak pelvis, ginjal dan jantung (Correction factor for hot carcass, back fat thickness, loin eye area and fat percentage of kidney, pelvic and heart).

Tabel 6. Frekuensi nilai perdagingan (USDA Yield Grade) sapi ACC dan BX dengan jenis kelamin berbeda (Frequency of fleshing of $A C C$ and $B X$ cattle)

\begin{tabular}{|c|c|c|c|c|c|c|}
\hline \multirow{3}{*}{ USDA Yield Grade } & \multicolumn{6}{|c|}{ Klasifikasi Jenis Kelamin ((Type of cattle) } \\
\hline & \multicolumn{2}{|c|}{ Cow } & \multicolumn{2}{|c|}{ Heifer } & \multicolumn{2}{|c|}{ Steer } \\
\hline & $\mathrm{n}$ & $\%$ & $\mathrm{n}$ & $\%$ & $\mathrm{n}$ & $\%$ \\
\hline YG 1 & 0 & 0 & 0 & 0 & 0 & 0 \\
\hline YG 2 & 0 & 0 & 0 & 0 & 0 & 0 \\
\hline YG 3 & 0 & 0 & 4 & 20.00 & 9 & 39.13 \\
\hline YG 4 & 4 & 18.18 & 13 & 65.00 & 8 & 34.78 \\
\hline YG 5 & 18 & 81.82 & 3 & 15.00 & 6 & 26.09 \\
\hline Jumlah (Total) & 22 & 100.00 & 20 & 100.00 & 23 & 100.00 \\
\hline
\end{tabular}

Perdagingan yang tinggi dengan perlemakan yang rendah dapat menunjukkan kualitas daging yang baik, tetapi hal ini tidak selalu berarti bahwa karkas tersebut memiliki kualitas yang baik ataupun sebaliknya. Hal ini dipengaruhi oleh tingkat kesukaan konsumen. Di Indonesia, konsumen lokal (pasar tradisional) lebih menyukai perdagingan yang tinggi dengan tingkat perlemakan yang rendah, namun sebaliknya konsumen khusus (seperti hotel dan waralaba) lebih menyukai tingkat perlemakan yang cukup tinggi.

\section{Kesimpulan}

Secara umum karakteristik karkas tidak dipengaruhi oleh jenis kelamin sapi kecuali pada persentase lemak pelvis, ginjal, dan jantung di mana cow nyata lebih besar dibandingkan heifer dan steer. Nilai potongan total daging primer berbeda pada potongan chuck dan round dimana steer dan heifer mempunyai persentase yang lebih tinggi dibandingkan cow, sedangkan total potongan daging sekunder pada steer lebih tinggi daripada heifer dan cow.

Terdapat perbedaan persentase nilai perdagingan jika berdasarkan rumus Murphey et al. (1960) di mana steer mempunyai nilai perdagingan lebih baik dibandingkan heifer dan cow. Persentase perdagingan berdasarkan penimbangan langsung tidak dipengaruhi jenis kelamin. Berdasarkan USDA Yield Grade, cow, heifer dan steer memiliki nilai yield grade 
antara 3 dan 5. Steer memiliki nilai yield grade 3 , heifer memiliki nilai yield grade 4 dan cow memiliki nilai yield grade 5 , hal ini menunjukkan bahwa perdagingan sapi steer lebih baik dibandingkan sapi heifer dan cow.

Persamaan Murphey et al. (1960) yang digunakan untuk menentukan nilai perdagingan (USDA Yield Grade) menunjukkan adanya perbedaan di antara jenis kelamin sapi sehingga perlu adanya faktor koreksi.

\section{Daftar Pustaka}

Australian Meat and Livestock Corporation. 2001. Handbook of Halal Indonesian Beef. $I^{ \pm}$Edition, APFINDO.

Burson, D. E. 1997. Quality abd yield grades for beef carcasses.http.//ianrpubs. unl.edu/beef/rp357.htm.

Griffin, D. B., J. W. Savell, J. B. Morgan, R. P. Garrret and H. R. Cross. 1992. Estimates of sbprimal yields from beef carcasses as affected by usda grades, subcutaneus fat trim level and carcass sex class and type. J.Anim. Sci. 70:2411-2430.

Hanson, D., C. Calkins, B. Gwartney, J. Forrest and $R$. Lemenager. 1999. The relationship of beef primal cut composition to overall carcass composition.http.//ianrpubs.unl.edu/bee f/report/mp71-30.htm.

Jones, D. R and W. C. Stringer. 1999. Beef carcass grading and evaluation. http.//muextension.missouri.edu/explor e/agguides/ansci/go 2220/htm.

Kempster, T., A. Cuthberston, and Harrington. 1982. Carcass Evaluation in Livestock Breeding, Production and Marketing. First Publ. Granada Publishing Ltd., Granada.

Murphey, C. E., D. K. Hallett, J. C. Pierce, and W. E. Tyler, 1960. Estimating yields of retail cuts from beef carcasses. J. Anim. Sci. 19: 1240 .

Preston, T. R. and M. B. Willis. 1982. Intensif Beef Production. Pergamon Press, Oxford, New York, Toronto, Sydney, Paris, Frankfurt.

Romans R. R., W. J. Costello, C. W. Carlson, M. L. Greaser and K. W. Jones. 1985. The Meat We Eat. Interstate Publishers, Inc., Danville, Illinois.

Steel, R. G. D., dan J. H. Torrie. 1993. Prinsip dan Prosedur Statistika, Suatu Pendekatan Biometrik. PT. Gramedia Pustaka Utama, Jakarta. 